\title{
Construction of a Simple Interactive System Based on Computer Vision Technology for Food and Agricultural Education
}

\author{
Chao-Ming Wang, Yu-Hui Lin \\ Department of Digital Media Design, National Yunlin University of Science \& Technology, \\ Douliu City, Yunlin County, Taiwan \\ Email: wangcm@yuntech.edu.tw (Chao-Ming Wang)
}

\begin{abstract}
An interactive system based on computer vision technology for food and agricultural education is proposed, on which knowledge of food cuisines can be learned by game playing using objectbased tangible interfaces. Specifically, cuisines with their ingredients are projected onto an interactive projection table for the user to learn when specially-designed objects attached with light-reflecting stickers are placed on the table and recognized by the system. Such objection recognition is realized by analyzing the shapes of the stickers appearing in the IR images taken by an infrared filter camera. The system was exhibited and observations of the users' performances as well as interviews with experts and the users were conducted. The collected data were used to evaluate the effectiveness of the system to reach the following conclusions: 1) the use of computer vision technology to carry out human-machine interaction offers a novel and interesting experiencing process; 2) the object-based interface helps the participants fit into the context of education; 3) the interactive experience of performing the system is appealing and amusing; and 4) the adopted projection mapping approach could be combined with richer dynamic images and more knowledge contents to enhance the educational effect.
\end{abstract}


Keywords: food and agricultural education, human-machine interaction, computer vision technology, interactive game playing, object recognition.

\section{Introduction}

The Food and Agriculture Organization (FAO) of the United Nations pointed out that agriculture not only has to provide people with food and clothing, but also needs to maintain sustainable operations while meeting social objectives of food safety, nutrition supplies, and health promotion [1]. The control of the food industry chain directly affects food safety, and people's choices of food also affect environmental sustainability [2-3]. Obviously, food is closely related to agriculture, so it is all people's responsibility to sustain the food and agriculture system. One way to advocate these concepts to the public is to convey the related knowledge from the perspective of food and agricultural education [4-5].

Food and agricultural education helps children grow up; if children can learn about the source and production of food, they can cultivate the ability to choose food correctly, laying the foundation for good eating habits [6]. For general consumers, food and agricultural education can enhance their sense of identity to the local agriculture and food culture, and promote their healthy diet life; and for producers, it can increase the opportunity to contact consumers, activate the local agricultural industry, and promote a good cycle of local productions for local consumption [7]. Therefore, food and agricultural education can be said to be a national movement; people of all ages have to accept food and agricultural education and form the altitude of lifelong learning of the related knowledge.

With the progress of science and technology, digital media have become an emerging approach to helping convey knowledge of various fields. Introducing digital media into the education domain can break the time and space constraints faced by traditional education, and simulate the experiencing situation related to the educational content; and by bringing interactive activities into the learning process, learners can acquire knowledge more efficiently [8]. In addition, the progress of information technology breaks the limitation between the physical space and the virtual space, constructing a communication bridge between the human and the machine [9], wherein computer vision technology provides new possibilities for human-machine interaction by conducting real-time operations and image analysis to simulate the human visual sense, imitate the ability of humans to identify objects, and perceive the surrounding environment [10]. More specifically, the application of computer vision technology in human-machine interaction 
aims at enabling users to trigger interaction mechanisms without touching objects like switches or buttons in the real world, enabling the development of human-machine interfaces that can be used in more natural and direct ways [11]. At present, somatosensory interaction technologies, such as skeleton detection, gesture recognition, face detection, facial expression analysis, eye tracking, etc., have been derived, which can be used in the applications of interactive projection, digital art, and so on [12-15]. Hsu [14] pointed out that the application of computer vision in education has great potentials, not only bringing learners interesting experiences of interactive learning, but also enhancing their willingness to participate. Geller [15] mentioned that computer vision technology, when combined with the uses of interactive projection desktops, can keep the mystery of the technology behind and cross the imagination space of the participants, bringing them amazing experience and pleasure of interaction.

The aim of this study is to utilize computer vision technology to design a simple system for food and agricultural education via the use of an interactive projection table, which can offer users the interactive game-playing experience of "using objects as the interface." In particular, the shapes of triangles, squares, pentagons, or circles are used as the object features in the interface, achieving the effect of simple and effective object recognition in the process of human-machine interaction.

\section{Literature Review}

In this section, literatures about food and agricultural education and the theory of humanmachine interaction will be reviewed, followed by a survey of computer vision technology and existing cases of related applications, from which the principles for designing the proposed system were derived.

\subsection{Food and Agricultural Education}

"Food education" was proposed very early by Sagen Ishizuka, a Japanese nutritionist, in his work, Food Regimen, in 1898, advocating the concept that people's physical and mental health is closely related to what they eat, and encouraging the practice of dietary education in daily life to reach balanced dieting and eating locally in seasons [16]. The broader concept of "food and agricultural education" was promoted by many USA public and private organizations and by the Japan's Ministry of Agriculture, Forestry and Fisheries [17-19], starting from 1970's.

Nobuhiko [20] suggested that food and agricultural education should not only integrate the experience related to "agriculture" and "diet," but also include the concept of environmental 
education, so as to make food and agricultural education a holistic education. By via food and agricultural education, a learner can understand the process of "food serving from the origin to the dining table." The National Association of Agricultural Educators (NAAE) in the United States regards learning by experiencing as an important way for food and agricultural education $[21]$.

\subsection{Human-machine Interaction}

Human-machine interaction is a research field about communication between "humans" and "machines." With the progress of communication technology and the improvement of computers, human-machine interaction has developed into many different forms, creating perfect connections between technology and human beings and providing users with new types of experience and fun [22-24].

Jaimes and Sebe [25] argued that some input modes of human-machine interfaces correspond to the human sensory systems; with proper peripherals like cameras, microphones, mobile devices, etc., computers can be used to simulate human sensory systems, contributing to the creation of many new interactive devices or systems for various applications. How to integrate the most appropriate interface to interact according to required situations and provide users with good system-usage experiences is a subject of importance in the field of interactive design [26]. Yeh [24] suggested that a good interactive design should follow the principles of "3e indicators," namely, "effectiveness," "easiness," and "enjoyment."

\subsection{Computer Vision}

The aim of computer vision technology, when applied to human-machine interaction, is mainly to locate objects in images [27]; for this purpose, Jaimes and Sebe [25] divided the process of detecting objects in continuous images by computer vision techniques into four stages, namely, motion segmentation, object classification, tracking, and interpretation. In the motion segmentation stage, a target in an image is firstly located and segmented out using techniques like background subtraction, frame differencing, optical flow, etc. [28]. In the object classification stage, each segmented target is recognized for subsequent tracking and interpretation of its behavior. Object classification methods are usually based on the uses of the information of shape, color, texture, and motion-based features in the image [29]. In the object tracking stage, the aim is to follow the path of an object as it moves. The methods adopted for object tracking may be classified into three categories: point-based, kernel-based, and silhouettebased [30].

Computer vision technology with "object" as the unit of the interface is based on the tangible 
interfacing concept [31]. By building an environmental space and placing physical objects into the field of view of the camera, computer vision techniques may be used to analyze the features of the appearances of the objects, such as special mark, color, shape, etc., to accomplish the tasks of confirming the existences of the objects, recognizing what the objects are, tracking their positions, and so on [32]. In this study, the computer vision interaction situations mentioned by Wang and $\mathrm{Wu}$ [33] are referred to so as to derive several possible manifestation forms of computer vision with "objects as the interface" as shown in Table 1 where the red dotted arrows in each figure represent the image-taking directions of the cameras.

Table 1. Manifestation forms of computer vision with "objects as interfaces."

\begin{tabular}{|c|c|c|c|}
\hline Manifestation & Illustration & Location of the camera & Sensing by computer vision \\
\hline $\begin{array}{c}\text { Interactive } \\
\text { wall }\end{array}$ & & $\begin{array}{l}\text { (1) Put on the table, facing forward to } \\
\text { take images. } \\
\text { (2) Hung on the wall, slightly tilted down } \\
\text { to take images. } \\
\text { (3) Hung behind the wall, facing forward } \\
\text { to take image. }\end{array}$ & $\begin{array}{l}\text { Sensing the object held in } \\
\text { hand by the participant, } \\
\text { followed by tracking and real- } \\
\text { time localization of it. }\end{array}$ \\
\hline $\begin{array}{c}\text { Interactive } \\
\text { table }\end{array}$ & 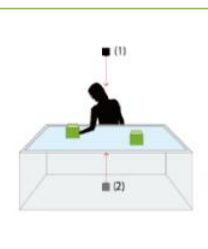 & $\begin{array}{l}\text { (1) Hung right above the participant } \\
\text { (2) Put underneath the table and operated } \\
\text { by the participant }\end{array}$ & $\begin{array}{l}\text { Sensing the outer } \\
\text { characteristics of the object on } \\
\text { the table, followed by tracking } \\
\text { and real-time localization of it }\end{array}$ \\
\hline $\begin{array}{c}\text { Interactive } \\
\text { floor }\end{array}$ & $\sqrt{1}=$ & Hung right above the standing participant. & $\begin{array}{l}\text { Sensing the outer } \\
\text { characteristics of the object on } \\
\text { the table, followed by tracking } \\
\text { and real-time localization of } \\
\text { it. }\end{array}$ \\
\hline
\end{tabular}

\subsection{Interactive Experience}

In human-machine interaction activities, the interactive experience is based on the user's cognition, emotion, and feeling, with the goal to promote the user's thinking, action, and pleasance [34]. Pine and Gilmore [35] think that the "pleasant experience" should cover four states, namely, esthetic, entertainment, educational, and escapist. With the popularization of technology, it has become a trend for museums to carry out educational exhibitions that offers interactive experiences. Mitchell et al. [36] suggested that if museum education in the 21 st century could integrate educators, professional knowledge, and digital media tools to form cross- 
field cooperation, it would be able to effectively attract more crowds to the exhibition. By simulating the situation of the teaching theme and introducing interactive experiences, exhibition education can effectively convey knowledge and enhance the interactivity between visitors and exhibitions.

\subsection{Related Case Studies of Computer Vision Applications}

Reviewed here are five existing works that offer the users interactive experiences via computer vision technology based on the concept of "using objects as the interface," with the adopted computer vision techniques and interactive modes listed in Table 2. In these cases, humanmachine interaction is accomplished by uses of interactive projection tables with invisible infrared light projection via computer vision techniques.

\subsection{Brief Description of the Proposed System}

The above literature survey provides reviews of various concepts and case studies about food and agricultural education, human-machine interaction, and computer vison technology. Based on these reviews, relevant principles for designing a system for food and agricultural education were derived. The principles were followed to construct a real system on which a game can be played to learn knowledge about the process of "food serving from the origin to the dining table" in a manner of high-freedom human-machine interaction. The system architecture is based on the projection mapping approach adopting an infrared filter camera and an infrared light projector, and the game is implemented by computer vision techniques utilizing a tangible object-based interface on an interactive projection table, as described in Table 3.

Table 2. Reviewed cases that introduce computer vision techniques into human-machine interfaces.

\begin{tabular}{|c|c|c|c|c|}
\hline Work & Illustration & $\begin{array}{c}\text { Computer vision } \\
\text { techniques }\end{array}$ & $\begin{array}{c}\text { Interface and/or } \\
\text { interaction }\end{array}$ & Explanation \\
\hline $\begin{array}{c}\text { ReacTable } \\
\text { [37] }\end{array}$ & & $\begin{array}{l}\text { image } \\
\text { segmentation } \\
\text { feature } \\
\text { analysis } \\
\text { object } \\
\text { recognition }\end{array}$ & $\begin{array}{l}\text { objects } \\
\text { and humans } \\
\text { hand and } \\
\text { finger positions }\end{array}$ & $\begin{array}{l}\text { Placing an object on the desktop } \\
\text { will yield a connection and sound } \\
\text { effects between the objects, and } \\
\text { the virtual interface next to the } \\
\text { object can be touched by the } \\
\text { finger. }\end{array}$ \\
\hline $\begin{array}{l}\text { A Table } \\
\text { where Little } \\
\text { People Live }\end{array}$ & & $\begin{array}{l}\text { image } \\
\text { segmentation } \\
\text { boundary }\end{array}$ & $\begin{array}{l}\text { objects } \\
\text { and humans } \\
\text { object and }\end{array}$ & $\begin{array}{l}\text { Putting hands or physical objects } \\
\text { on the interactive projection table } \\
\text { will cause the little people in the } \\
\text { graphic projected on the table to }\end{array}$ \\
\hline
\end{tabular}




\begin{tabular}{|c|c|c|c|}
\hline [38] & 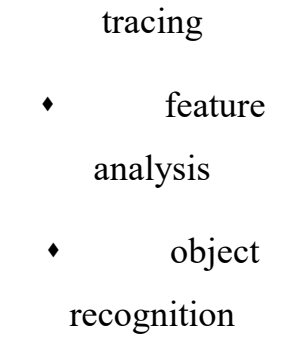 & $\begin{array}{l}\text { hand positions } \\
\text { object or } \\
\text { hand silhouettes }\end{array}$ & $\begin{array}{l}\text { climb and jump to the top, } \\
\text { forming physical collisions. }\end{array}$ \\
\hline $\begin{array}{l}\text { Worlds } \\
\text { Unleashed } \\
\text { and then } \\
\text { Connecting } \\
\text { [39] }\end{array}$ & 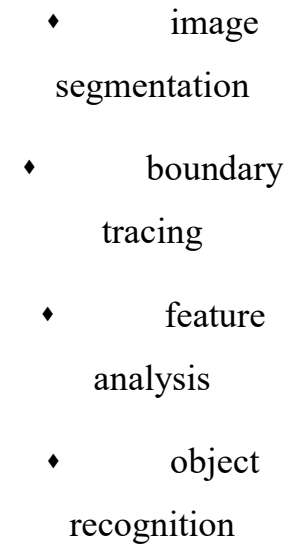 & $\begin{array}{l}\text { - } \\
\text { - } \quad \text { objects } \\
\text { positions } \\
\text { - } \quad \text { object } \\
\text { contours }\end{array}$ & $\begin{array}{l}\text { Placing the utensils on the dining } \\
\text { table, and the system will project } \\
\text { corresponding dynamic effects } \\
\text { along the edges of the utensils } \\
\text { according to the type of utensils. }\end{array}$ \\
\hline $\begin{array}{c}\text { Connecting! } \\
\text { Block Town } \\
{[40]}\end{array}$ & $\begin{array}{l}\text { image } \\
\text { segmentation } \\
\text { - color } \\
\text { identification } \\
\text { object } \\
\text { recognition }\end{array}$ & $\begin{array}{l}\text { objects } \\
\text { positions } \\
\text { No. of on- } \\
\text { table objects }\end{array}$ & $\begin{array}{l}\text { Placing similar objects on the } \\
\text { interactive table will create the } \\
\text { events that the houses will be } \\
\text { connected, and that special } \\
\text { transportation effects will appear, } \\
\text { and be upgraded as more objects } \\
\text { are placed. }\end{array}$ \\
\hline $\begin{array}{l}\text { Happy } \\
\text { Farmer }\end{array}$ & $\begin{array}{l}\text { image } \\
\text { segmentation } \\
\text { feature } \\
\text { analysis } \\
\text { contour } \\
\text { classification } \\
\text { object } \\
\text { recognition }\end{array}$ & 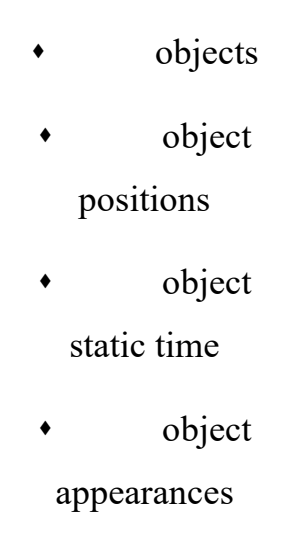 & $\begin{array}{l}\text { Placing objects on the desktop } \\
\text { will cause reading and seeding; } \\
\text { using different numbers of } \\
\text { reflective stickers can trigger } \\
\text { object recognition; and covering } \\
\text { reflective stickers by hands can } \\
\text { switch crops. }\end{array}$ \\
\hline
\end{tabular}


Table 3. Design of the proposed system using an interactive projection table for food and agricultural education.

\begin{tabular}{|c|c|c|c|c|}
\hline Work & Interface and interaction & Equipment & $\begin{array}{c}\text { Computer vison } \\
\text { techniques }\end{array}$ & Scenario \\
\hline $\begin{array}{l}\text { The proposed } \\
\text { system with an } \\
\text { interactive } \\
\text { projection table }\end{array}$ & $\begin{array}{l}\text { Interacting with "objects" } \\
\text { placed on the table by } \\
\text { recognizing the shape patterns } \\
\text { of stickers attached on the } \\
\text { objects in the IR images formed } \\
\text { by reflected IR light }\end{array}$ & $\begin{array}{l}\text { Infrared } \\
\text { filter camera } \\
\text { infrared } \\
\text { light projector }\end{array}$ & $\begin{array}{l}\text { Image } \\
\text { segmentation } \\
\text { Feature } \\
\text { analysis } \\
\text { Object } \\
\text { recognition }\end{array}$ & $\begin{array}{l}\text { "Food serving } \\
\text { from the origin } \\
\text { to the table" }\end{array}$ \\
\hline
\end{tabular}

\section{Methods}

The methods used in this study are introduced here, including the methods of prototyping, observation, and interview, and that used to construct the proposed system which can offer users the interactive game-playing experience of "using objects as the interface."

\subsection{The Prototyping Method}

Prototyping is a quick and low-cost way to evaluate a system before it is formally constructed [42]. Referring to the prototyping process proposed by Naumann and Jenkins [43] and Eliason [44], an interactive prototype system for conducting food and agricultural education was constructed and improved in this study according to the following four steps: (1) conducting a survey of related literatures; (2) deriving design principles for the desired prototype; (3) carrying out relevant experiments; and (4) evaluating the effectiveness of the prototype according to users' comments; and (5) improving the prototype for further testing. The resulting formal system, called "iFood on iTable," was descripted in Sec3.5. This proposed system offers users the interactive game-playing experience of "using objects as the interface." In particular, the shapes of triangles, squares, pentagons, or circles are used as the object features in the interface.

\subsection{The Observation Method}

In the observation method, qualitative analysis is used to conduct subtle observations of the users' performances and collect relevant data from the perspectives of onlookers [45]. In this study, this method was adopted to understand the situations and behaviors of the participants while they were using the proposed system. Specifically, observations were conducted from the two aspects of "operation situation of human-machine interface" and "participant's behavior." 
The observation results will be used for further improvement on the proposed system.

\subsection{The Interview Method with Users as the Interviewees}

In an interview method, invited interviewees are asked questions about the needs of the survey and objective facts are collected through their answers [46]. This method was used in this study in two ways, namely, interviews with users and interviews with experts. The former is described here. Specifically, 50 participants were randomly selected in this study for interviews during the public exhibition of the proposed system, aiming at collecting the participants' comments for verifying the effectiveness of the proposed system. The "3e indicators" proposed by Yeh [24], namely, "effectiveness," "easiness," and "enjoyment," as well as the "four states of pleasant experience" proposed by Pine and Gilmore [35], namely, "esthetic," "entertainment," "educational," and "escapist" were adopted to design the questions asked in the interview process, resulting questions about three aspects: "operation situation of human-machine interface," "operation experience," and "views on interactive experience of food and agricultural education," where (1) the aspect of "operation situation of human-machine interface" comes from the two indicators of "easiness" and "effectiveness"; (2) the aspect of "operation experience" comes from the "enjoyment" indicator and the "esthetic" and "educational" states; and (3) the aspect of "views on interactive experience of food and agricultural education" is aimed at covering the remaining "entertainment" and "escapist" states. The comments collected from the user interviews will be presented later in this paper.

\subsection{The Interview Method with Experts as the Interviewees}

In this study, four experts were invited and interviewed before and after each user's experiencing process using the proposed system in the public exhibition of the system. The experts' backgrounds are shown in Table 4 . Their comments will be presented later.

Table 4. Experts interviewed in the public exhibition of the proposed system.

\begin{tabular}{cccc}
\hline Code & Appointment Unit & Title & Expertise \\
\hline A & An elementary school & Teacher & $\begin{array}{c}\text { child education, food and agriculture } \\
\text { education, information technology }\end{array}$ \\
\hline B & Dept. of digital media design at a & Associate & digital learning, game design, information \\
& national university & professor & education \\
C & Dept. of digital media design at a & Professor & situational interactive design, creative \\
& national university & & thinking, user experience \\
\hline D & Dept. of creative life at a national & Assistant & design cognition psychology, social design, \\
\hline
\end{tabular}




\subsection{Construction of the Proposed System "iFood on iTable"}

The details about the construction of the proposed system are described in this section, including the design principle, architecture, hardware, software, and game-play process.

\subsubsection{Principles for Designing the Proposed System}

People's daily life depends on eating various types of food, which are often cooked according to certain cuisines and made from a variety of ingredients. The purpose of food and agricultural education via the proposed system is to teach the public the knowledge of "food serving from the origin to the dining table," i.e., to let the people to understand how a dish of food on a dining table is prepared by use of certain ingredients according to a cuisine. This teaching function of the system is implemented as an interactive game-play process conducted on the proposed system. The main ingredients adopted for use in the game include three crops, namely, rice, corn, and tomato, which are seen commonly in people's daily life. Based on these crops taken as the origins of food, nine cuisines are introduced in the game played on the proposed system from which the participant can learn to know how some commonly-seen dishes of gourmet are prepared according to these cuisines, as illustrated in Table 5. For example, the cuisine of tomato beef soup is shown in Table 6, which include, in addition to the main ingredient of tomato, five other ingredients, namely, beef ribs, potato, onion, salt, and water, with the quantities of the ingredients also listed.

Table 5. The nine cuisines taught by the proposed system in a game-playing manner.

\begin{tabular}{cccc}
\hline $\begin{array}{c}\text { Class (main } \\
\text { ingredient) }\end{array}$ & Type of dish & Name of cuisine & Illustration \\
\hline & A. staple & grilled corn & \\
\cline { 2 - 3 } corn & B. soup & corn chowder & \\
\cline { 2 - 3 } & C. dessert & snowflake cake \\
\hline A. staple & glutinous oil rice \\
\hline & B. soup & minced pork congee with preserved \\
\hline
\end{tabular}




\begin{tabular}{ccc}
\hline & A. staple & tomato scrambled eggs \\
\cline { 2 - 3 } tomato & B. soup & tomato beef soup \\
\cline { 2 - 3 } & C. dessert & tomato candied \\
\hline
\end{tabular}

Table 6. An example of cuisines - tomato beef soup and its ingredients.

\begin{tabular}{|c|c|c|c|c|c|c|c|}
\hline \multirow[t]{2}{*}{ Cuisine } & Dish & \multicolumn{3}{|c|}{ Tableware } & \multicolumn{3}{|c|}{ Ingredients } \\
\hline & Name & tomato & $\begin{array}{l}\text { beef } \\
\text { ribs }\end{array}$ & potato & onion & salt & water \\
\hline beef & Illustration & & & & & & \\
\hline & Quantity & two & $550 \mathrm{gm}$ & two & one & moderate & $\begin{array}{c}1000 \\
\mathrm{ml}\end{array}$ \\
\hline
\end{tabular}

There needs a certain way to display the knowledge of the cuisines described previously to the participant in the game-play process. The approach adopted in this study for this purpose is projection mapping [47], which is realized by infrared (IR) image analysis using computer vison techniques. Also needs in the proposed system is a certain way of interaction with the participant during the game-play process. The approach adopted by the system is tangible interfacing [31] using specially-designed objects.

To implement the ideas just mentioned, the environment of the proposed system is set up to be as illustrated by Figure 1 and Table 7, where Figure 1(a) shows a sideview of the system including the following items:

(1) an interactive projection table - for interaction with the participant;

(2) an overhead projector - for projecting the graphics of taught food knowledge on the table;

(3) an infrared light projector - for projecting IR light onto the objects placed on the table;

(4) an infrared filter camera - for taking the IR image of the content projected on the table with the image mainly formed by the IR light patterns reflected by the stickers attached to the game-control objects introduced next;

(5) four game-control objects - including a crop dice, a staple plate, a soup plate, and a dessert plate, together called food plates, as shown in the lower part of Figure 1(b) and in 
Column 1 of Table 7 for game control in human-machine interfacing;

(6) the crop dice - a cube with six faces attached with light-reflecting stackers of three distinct simple shapes, namely, triangle, square, and pentagon (as shown in Column 4 of Table 7) corresponding to the three crops of corn, rice, and tomato, respectively, which may be selected randomly by the user by free dice flipping as the main ingredient of three preferred cuisines (as shown in Table 5); and

(7) the three food plates - with their upward faces attached with light-reflecting stackers of the simple shapes of one, three, and seven circular dots (as shown in Column 4 of Table 7), which may be selected by the user to get the corresponding cuisine with the crop chosen above as the main ingredient.

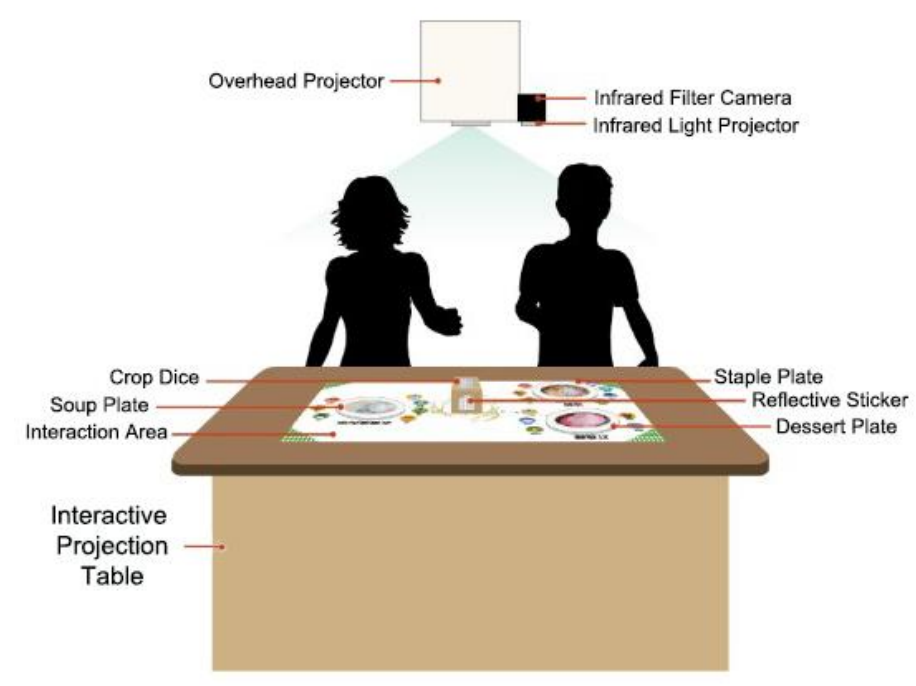

(a)

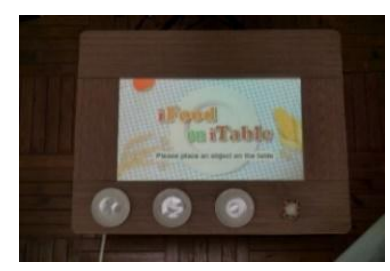

(b)

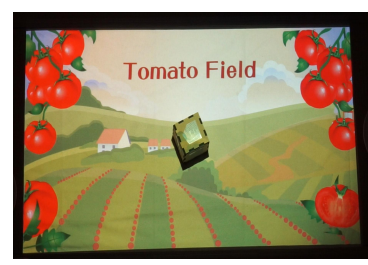

(c)

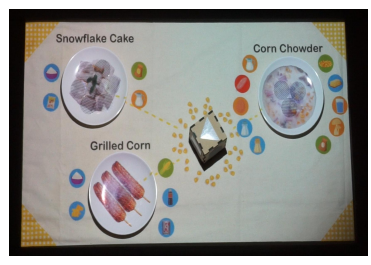

(d)

Figure 1. Environment of game playing on the proposed system. (a) A sideview of the system. (b) A view of the initial game screen projected on the interaction area on the interactive projection table with the game-control objects used in this study being shown at the lower part. (c) The graphic of the "tomato field" corresponding to the chosen main ingredient "tomato" projected into the projection area. (c) The interaction area is "filled up" with projected stuffs of the three cuisines using "tomato" as the main ingredient. 
Table 7. Simple patterns of reflective stickers attached to the game-control objects.

\begin{tabular}{|c|c|c|c|}
\hline Game-control object & Type & $\begin{array}{c}\text { Pattern of IR light-reflecting } \\
\text { stickers }\end{array}$ & $\begin{array}{c}\text { Characteristics of the } \\
\text { pattern }\end{array}$ \\
\hline & $\begin{array}{l}\text { triangle } \\
\text { (corn) }\end{array}$ & & $\begin{array}{l}\text { area:1000-2600 } \\
\text { No. of corners: } 3\end{array}$ \\
\hline & $\begin{array}{l}\text { square } \\
\text { (rice) }\end{array}$ & & $\begin{array}{l}\text { area: } 1000-2600 \\
\text { No. of corners: } 4\end{array}$ \\
\hline & $\begin{array}{l}\text { pentagon } \\
\text { (tomato) }\end{array}$ & & $\begin{array}{l}\text { area: } 1000-2600 \\
\text { No. of corners: } 5\end{array}$ \\
\hline & $\begin{array}{l}\text { one dot } \\
\text { (staple dish) }\end{array}$ & & $\begin{array}{l}\text { area: } 1000-2600 \\
\text { No. of corners: } 0\end{array}$ \\
\hline & $\begin{array}{l}\text { three dots } \\
\text { (soup dish) }\end{array}$ & & $\begin{array}{l}\text { area: } 3900-5500 \\
\text { No. of corners: } 0\end{array}$ \\
\hline & $\begin{array}{c}\text { seven dots } \\
\text { (dessert dish) }\end{array}$ & & $\begin{array}{l}\text { area: 大於 } 8000 \\
\text { No. of corners: } 0\end{array}$ \\
\hline
\end{tabular}

\subsubsection{The Game-play Process on the Proposed System}

The game played on the proposed system for food and agricultural education is illustrated briefly by Figures 1(b) 1(d) and is introduced briefly in the following:

(1) the user flips the crop dice freely on the interaction area of the interactive projection table;

(2) the system uses the infrared filter camera to acquire an IR image of the IR light reflected by the sticker attached on the upward face of the dice;

(3) the system analyzes the IR image to decide the simple shape (triangle, square, or pentagon) appearing in the image and projects the graphic of the corresponding farm field (corn, rice, or tomato) onto the interaction area on the interactive projection table;

(4) the user interacts further by placing one to three food plates in the interaction area on the table;

(5) the system acquires an IR image and analyzes it to find out the dot pattern (one, three or seven dots) on each placed plate and projects the graphic(s) of the corresponding cuisine(s) onto the table for the user to learn. 
The brief game-play process mentioned above is elaborated as an algorithm (Algorithm 1) in the following, where

(1) the action of acquiring an image of the interaction area is carried out using the infrared filter camera;

(2) the action of displaying a screen, a farm field, or a cuisine means to project the graphic of the respective content onto the interaction area on the interactive projection table;

(3) the variable cube face_shape is defined to be the type of shape on the upward face of the cube;

(4) an image segmentation process named ISP and an object recognition process named ORP developed in this study (to be described later) are assumed to be available for use in the algorithm.

Some examples of the graphic outputs yielded by running the algorithm are shown in Table 8 .

Algorithm 1. The process of game playing for food and agricultural education using the system "iFood on iTable."

Input: none.

Output: the graphics projected onto the interactive projection table like those shown in Column 3 of Table 8 .

\section{Steps.}

\section{//Stage 1: initialization ---}

\section{Step 1:}

display the initial game screen on to the interactive projection table.

//The screen is as shown in Figure 1(b) with a message asking the user to place a game-control object on the table

\section{//Stage 2: detecting the existence of the dice flipped on the interactive projection table ---}

\section{Step 2:}

2.1 acquire an image $I$ of the interaction area;

2.2 apply the image segmentation process $I S P$ to extract the objects existing in $I$;

2.3 If no object is not found in I then set variable cube_face_shape = "empty";

//Indicating that the crop dice is not flipped onto the table yet 
else

(a) apply the object recognition process $O R P$ to recognize the shape on the upward dice face;

(b) set variable cube_face_shape to be the found shape.

\section{//Stage 3: deciding the main ingredient of the desired cuisines ---}

\section{Step 3:}

case based on cube_face_shape:

(a) case "triangle"://The main ingredient "corn" is chosen

(i) display the "corn field" on the interaction area;

(ii) acquire an image $I$ of the interaction area;

(iii) apply the image segmentation process $I S P$ to extract the objects existing in $I$;

(iv) if no object is found in I then goto Step 3(a)(ii);//Repeating image acquisition

else apply the object recognition process $O R P$ to recognize the food plate(s) in $I$ in the following way:

(1) if a 1-dot pattern is found then display the cuisine "grilled corn"; end if;

(2) if a 3-dot pattern is found then display the cuisine "corn chowder"; end if;

(3) if a 7-dot pattern is found then display the cuisine "snowflake cake"; end if;

end if;

(b) case "square"://The main ingredient "rice" is chosen

(i) display the "rice field" on the interaction area;

(ii) acquire an image $I$ of the interaction area;

(iii) apply the image segmentation process $I S P$ to extract the objects existing in $I$;

(iv) if no object is found in I then goto Step 3(b)(ii);//Repeating image acquisition

else apply the object recognition process $O R P$ to identify the food plate(s) in $I$ in the following way:

(1) if a 1-dot pattern is found then display the cuisine "glutinous oil rice"; end if;

(2) if a 3-dot pattern is found then display the cuisine "minced pork congee with preserved egg"; end if; 
(3) if a 7-dot pattern is found then display the cuisine "red turtle cake"; end if;

end if;

(c) case "pentagon": //The main ingredient "tomato" is chosen

(i) display the "tomato field" on the interaction area;

(ii) acquire an image $I_{2}$ of the interaction area;

(iii) apply the image segmentation process $I S P$ to extract the objects existing in $I$;

(iv) if no object is found in I then goto Step 3(c)(ii); //Repeating image acquisition

else apply the object recognition process $O R P$ to identify the food plate(s) in $I$ in the following way:

(1) if a 1-dot pattern is found then display the cuisine "tomato scrambled eggs"; end if;

(2) if a 3-dot pattern is found then display the cuisine "tomato beef soup"; end if;

(3) if a 7-dot pattern is found then display the cuisine "tomato candied"; end if;

end if;

(d) case "empty": //The dice is not found on the projection table yet

display the screen of the "empty dining table" on the interaction area;

end case.

//Stage 4: repeating image acquisition to play the game again ---

Step 4: goto Step 2.

Table 8. Examples of output graphics of Algorithm 1.

\begin{tabular}{|c|c|c|c|c|}
\hline $\begin{array}{l}\text { Shape(s) } \\
\text { detected }\end{array}$ & Scenario & Illustration & Explanation & $\begin{array}{c}\text { Step in } \\
\text { Algorithm } 1\end{array}$ \\
\hline None & Initial game screen & 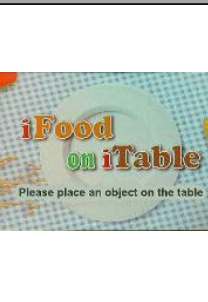 & $\begin{array}{l}\text { No object is placed on the } \\
\text { interactive projection table and } \\
\text { the game program is in the initial } \\
\text { state (displaying the initial game } \\
\text { screen). }\end{array}$ & Step 1 \\
\hline triangle & Corn field & & $\begin{array}{l}\text { The upward dice face is a } \\
\text { "triangle" meaning that "corn" is } \\
\text { chosen as the main ingredient for } \\
\text { food dishes, and a corn field is }\end{array}$ & Step 3(a)(i) \\
\hline
\end{tabular}


projected onto the interactive

projection table.

\begin{tabular}{|c|c|c|c|c|}
\hline square & Rice field & Paddr Field & $\begin{array}{l}\text { The upward dice face is a } \\
\text { "square" meaning that "rice" is } \\
\text { chosen as the main ingredient for } \\
\text { food dishes, and a rice field is } \\
\text { projected onto the interactive } \\
\text { projection table. }\end{array}$ & Step 3(b)(i) \\
\hline pentagon & Tomato field & 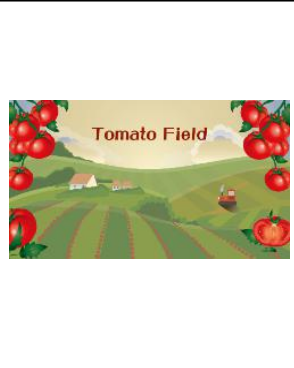 & $\begin{array}{l}\text { The upward cube face is a } \\
\text { "pentagon" meaning that } \\
\text { "tomato" is chosen as the main } \\
\text { ingredient for food dishes, and a } \\
\text { rice field is projected onto the } \\
\text { interactive projection table. }\end{array}$ & Step 3(c)(i) \\
\hline $1 / 3 / 7$ & $\begin{array}{l}\text { Dishes with main } \\
\text { ingredient of } \\
\text { "corn": } \\
\text { (1) grilled corn } \\
\text { (2) corn chowder } \\
\text { (3) snowflake cake }\end{array}$ & $: 4:$ & $\begin{array}{l}\text { The upward dice face is } \\
\text { "triangle" and all the three food } \\
\text { plates are placed on the } \\
\text { interactive projection table, } \\
\text { meaning that all three cuisines } \\
\text { related to the main ingredient of } \\
\text { "corn" are chosen to display for } \\
\text { the user to learn. }\end{array}$ & Step 3(a)(iv) \\
\hline
\end{tabular}

\section{Dishes with main}

ingredient of

"rice":

square
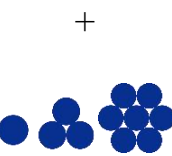

$1 / 3 / 7$

$\operatorname{dot}(\mathrm{s})$
(1) glutinous oil rice

(2) minced pork preserved egg congee with

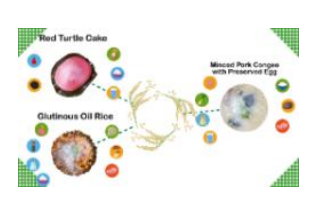

The upward dice face is "square" and all the three food plates are

placed on the interactive projection table, meaning that all the three cuisines related to the main ingredient of "rice" are chosen to display for the user to learn.
Step 3(b)(iv)

(3) red turtle cake

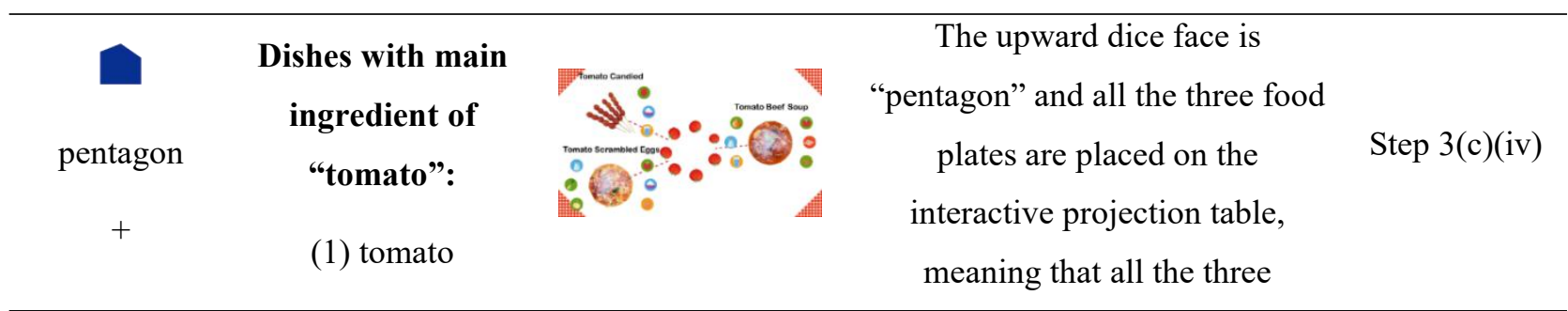




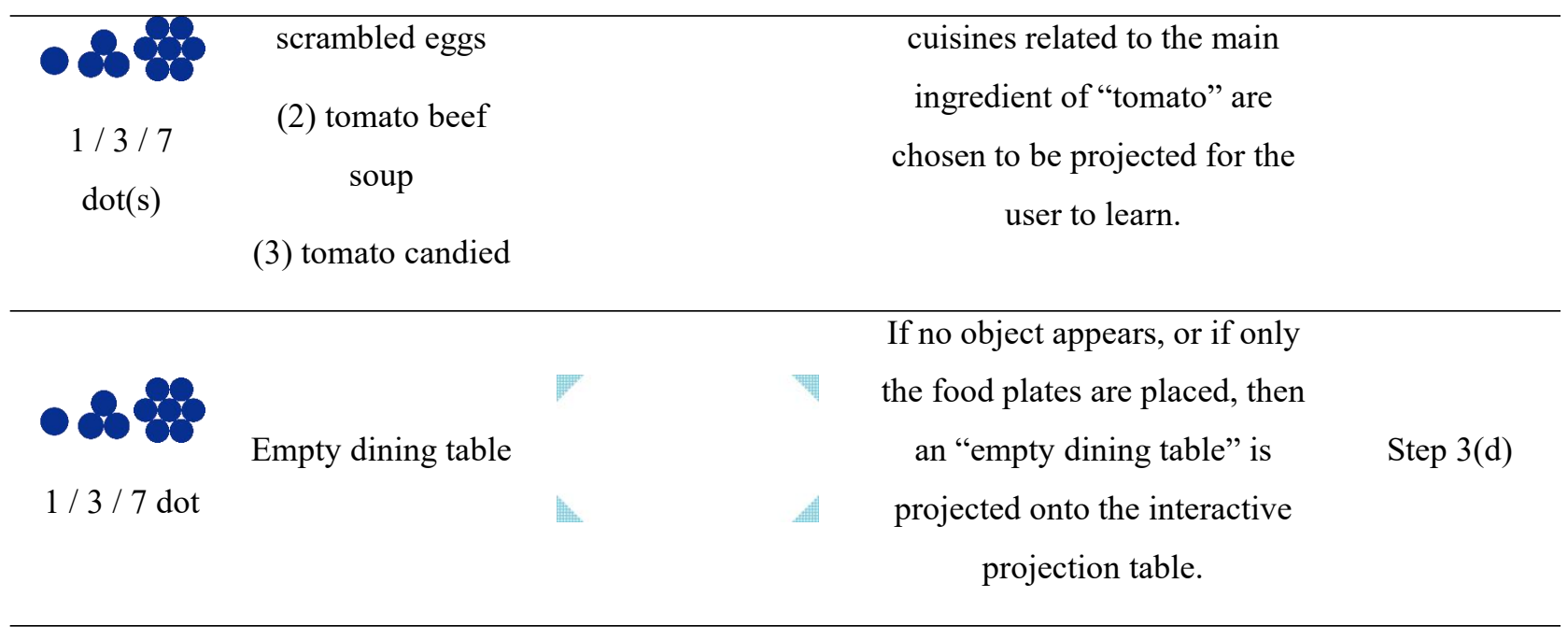

\subsubsection{Architecture of the Proposed System}

To realize the game-play process carried out by Algorithm 1, computer vision functions are needed, which are supported by the architecture of the proposed system as shown in Figure 2(a). The software part of the architecture includes a Unity3D game engine with the computer vision function library OpenCV3 which are used to implement the computer vision functions of "image segmentation" and "object recognition" used in Algorithm 1 for interaction with the user.

The hardware part has mostly been introduced previously, and as illustrate by Figure 2(b), they are used to perform the following functions:

(1) the infrared projector projects IR light onto the interactive projection table all the time;

(2) the reflective stickers affixed to the game-control objects, which are placed on the table by the user freely, reflects the IR light;

(3) the infrared filter camera senses the reflected light to form the IR image of the shapes of the stickers;

(4) the game program, Algorithm 1, is run to recognize the game-control objects according to the shapes and sizes of the stickers, emitting corresponding output graphics; and

(5) the overhead projector projects the graphic outputs like those shown in Column 3 of Table 8 onto the interaction area (regarded as a dining table in the game) on the interactive projection table. 


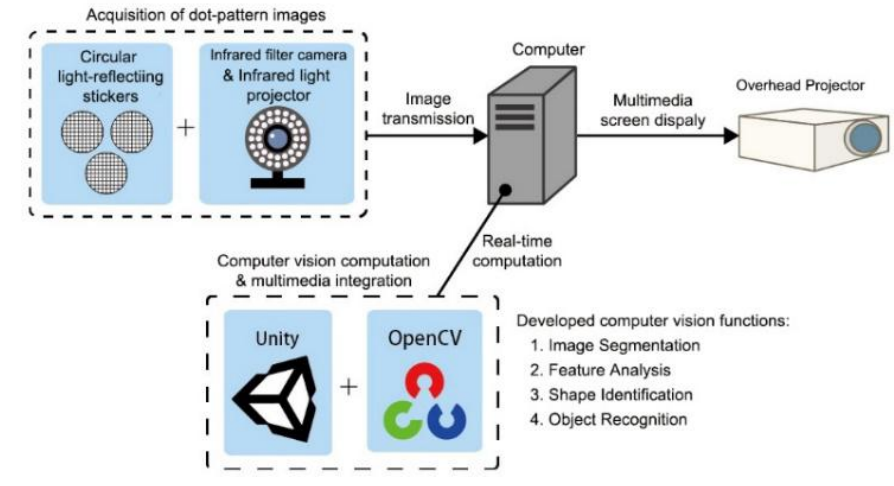

(a)

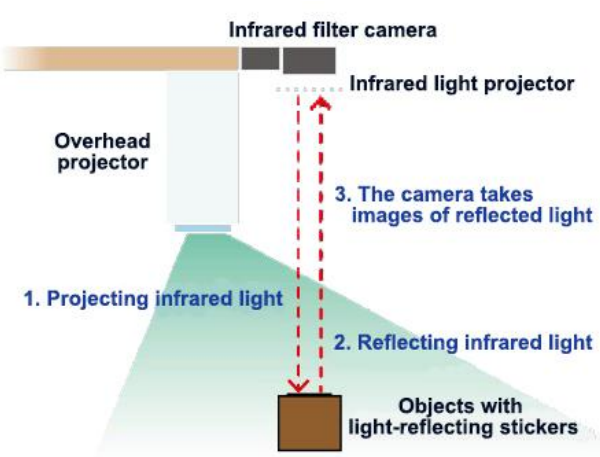

(b)

Figure 2. The architecture of the proposed system. (a) The hardware and software implementing the game program of Algorithm 1 for human-machine interaction. (b) An illustration of the principles of IR light projection and IR image acquisition.

\section{A. The Infrared Filter Camera}

To allow a camera to "see" the image formed by the IR light reflected by the stickers as mentioned above, in this study an ordinary three-axis zoom webcam was converted into an infrared filter camera by installing an infrared-pass filter between the imaging sensor of the webcam and the camera lens, as shown in Figures 3(a) and 3(b). The resulting imaging effect can be shown by Figures 3(c) and 3(d) where two images taken by the webcam and the infrared filter camera, respectively, are compared to clearly indicate that only the shapes of the stickers (consisting of small circular dots) attached to the game-control objects seen in Figure 3(c) reflect the projected IR light to form the IR image of Figure 3(d), i.e., only the simple white dot patterns can appear in the IR image, which so can be extracted and recognized more easily by computer vision techniques, as conducted in this study (described later in this paper).

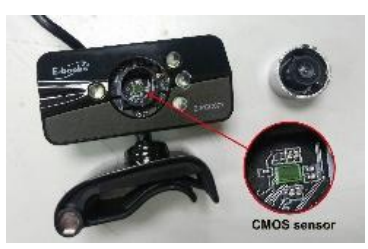

(a)

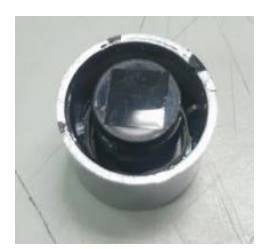

(b)

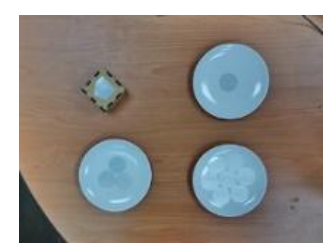

(c)

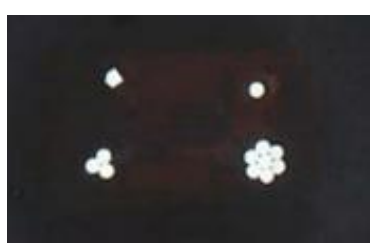

(d)

Figure 3. Modification of a webcam into an infrared filter camera for taking images of reflected infrared light. (a) Locating the imaging sensor. (b) Adding an IR-pass filter before the imaging sensor. (c) An image taken by a webcam of the game-control objects (the dice and the three food plates) attached with light-reflecting stickers. (d) An IR image taken by the infrared filter camera of the game-control objects in (c) which are much simpler to analyze. 


\section{B. Camera Calibration}

The combination of the infrared filter camera and the infrared light projector set up for IR image taking as well as the overhead projector for projecting the graphic outputs of Algorithm 1 together form a desktop projection device over the interactive projection table, as shown in Figure 4(a). The position of this device over the table and the direction of the camera must be calibrated, as was done in this study, in such a way that the lengths of the two shorter sides of the interaction area (each side being formed by a pair of L-shaped corners) as shown in Figure 4(b) become roughly equal. This task of camera calibration must be completed before the desktop projection device can be used for image acquisition, which is accomplished in this study by moving the interactive projection table gradually around and adjusting the axial direction of the camera until the center point of the interaction area surrounded by four L-shaped corners appears approximately in the middle of the taken image and the lengths of the left and right sides of the interaction area were roughly the same.

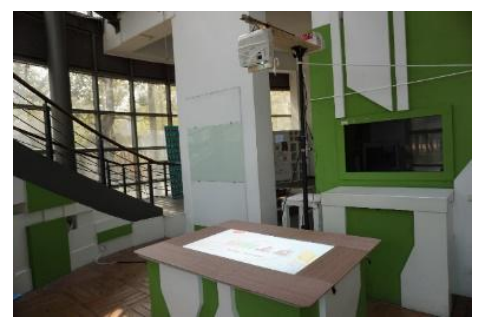

(a)

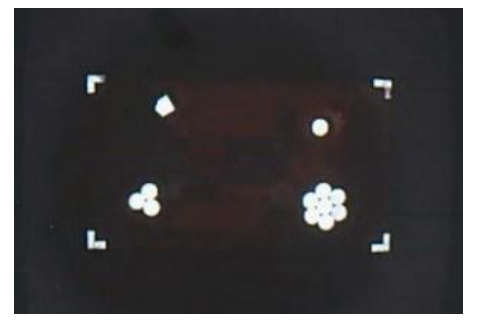

(b)

Figure 4. Infrared Camera Calibration. (a) The desktop projection device hung over the interactive projection table. (b) An IR image taken with the infrared filter camera after camera calibration is completed, with the left and right sides of the interaction area having equal lengths in the image.

\subsubsection{Algorithms of the Computer Vision Functions of the Proposed System}

The aforementioned image segmentation process $I S P$ and the object recognition process $O B J$ implemented in this study for use in the human-machine interaction process implemented by Algorithm 1 are described in this section.

\section{A. Image segmentation}

In the proposed image segmentation process ISP, with an IR image like that of Figure 5(a) acquired by the infrared filter camera with a $1280 \times 960$ resolution as the input, at first the interaction area on the interactive projection table enclosed by the L-shaped reflective stickers, called the rectangular region of interest (ROI), with an $800 \times 450$ resolution is extracted from the 
acquired image. Then, the connected components in the ROI are extracted and enclosed by green lines. Finally, the coordinates of the centroid of each component and its area are computed. All these steps can be implemented readily by uses of appropriate functions of the library OpenCV such as the connected component extraction function connectedComponentsWithStats(). This image segmentation process ISP is used in Steps 2.2, 3(a)(iii), 3(b)(iii), and 3(c)(iii) in Algorithm 1 presented previously. An example of the image segmentation results is shown in Figure 5(b).

\section{B. Object Recognition}

A total of six different shapes (three polygonal shapes and three dot-pattern shapes) formed by reflective light from the light-reflecting stickers, like the those shown in Figure 5(a), can be found in the image taken by the infrared filter camera. Such simple shapes can be recognized in this study using different figures of the shapes. The process developed for this purpose is shown in Figure 6 as a flowchart, in which the used features include area, number of corns, etc. and the used basic functions include contour finding, polygon approximation, etc. These features and functions can be extracted or performed by the previously-mentioned image segmentation process and some functions provided by the software OpenCV such as findContours(), approxPolyDP(), etc. This object recognition process named $O R P$ is used in Steps 2.3, 3(a)(iv), 3(b)(iv), 3(c)(iv) of Algorithm 1 for "detecting the existence of the game-control objects (the crop dice and the three food plates)."

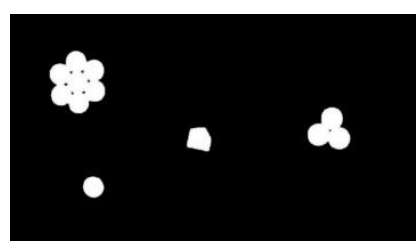

(a)

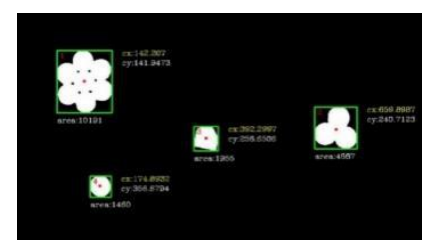

(b)

Figure 5. An example of image segmentation results. 


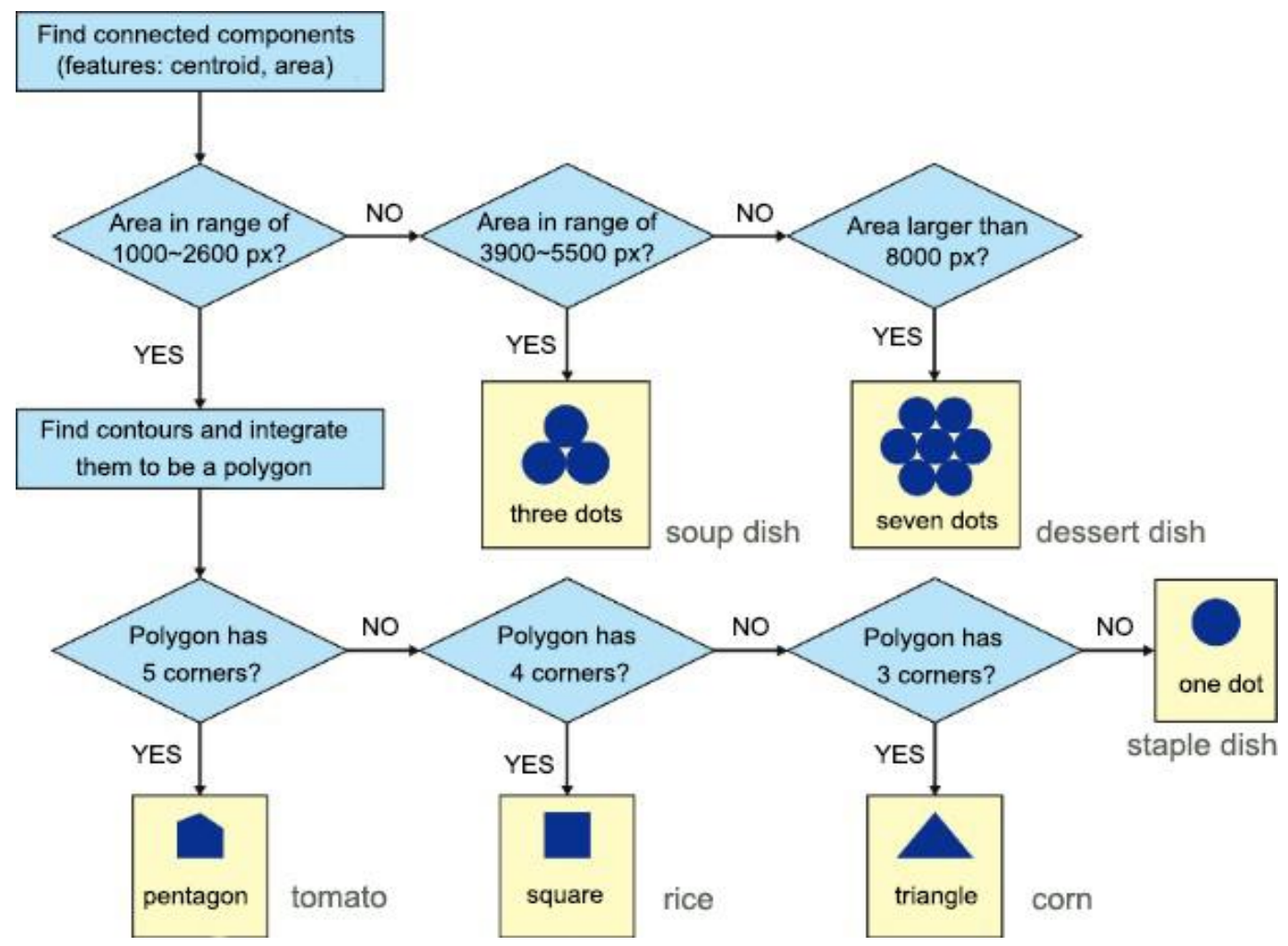

Figure 6. Procedure of object recognition by feature analysis using the IR images of the stickers by simple patterns attached on the game-control objects.

\section{Results and Discussions}

The proposed system was exhibited publicly in the design museum of a national university for 10 days, and 50 participants from the public older than the age of 18 and four experts were invited to experience the proposed system. An experiencing activity lasts about 25 minutes, including 5 minutes to introduce the system to the participant, 10 minutes carrying out for the game-play process, and 10 minutes for an interview with the user. During the game-play process, each user's interaction was observed and recorded. Afterwards, some non-expert users were randomly selected for interviews with their comments being collected.

\subsection{Analysis of Observed Users' Behaviors for Evaluating the Experiencing Process}

The participants who performed the proposed system were observed during the public exhibition period by video recording as well as pens and paper. The observation was conducted from two aspects: "operation situation of human-machine interface" and "participant's behavior." The results are listed in Table 9 which is summarized in the following.

(1) The participants were attracted by the interaction of the system, finding it interesting and 
repeatedly placing, flipping, or moving the game-control objects.

(2) The outer face of the dice could make the participants easily think of the function of the dice.

(3) It is easy to affect the accuracy of object recognition by masking the reflective stickers, which may be improved by moving the camera to be underneath the table.

(4) More information for food and agricultural education can be given on the screen of the farmland introduction to attract the participants' vision for a longer time.

Table 9. Observation results of the users' performances of the proposed system "iFood on iTable."

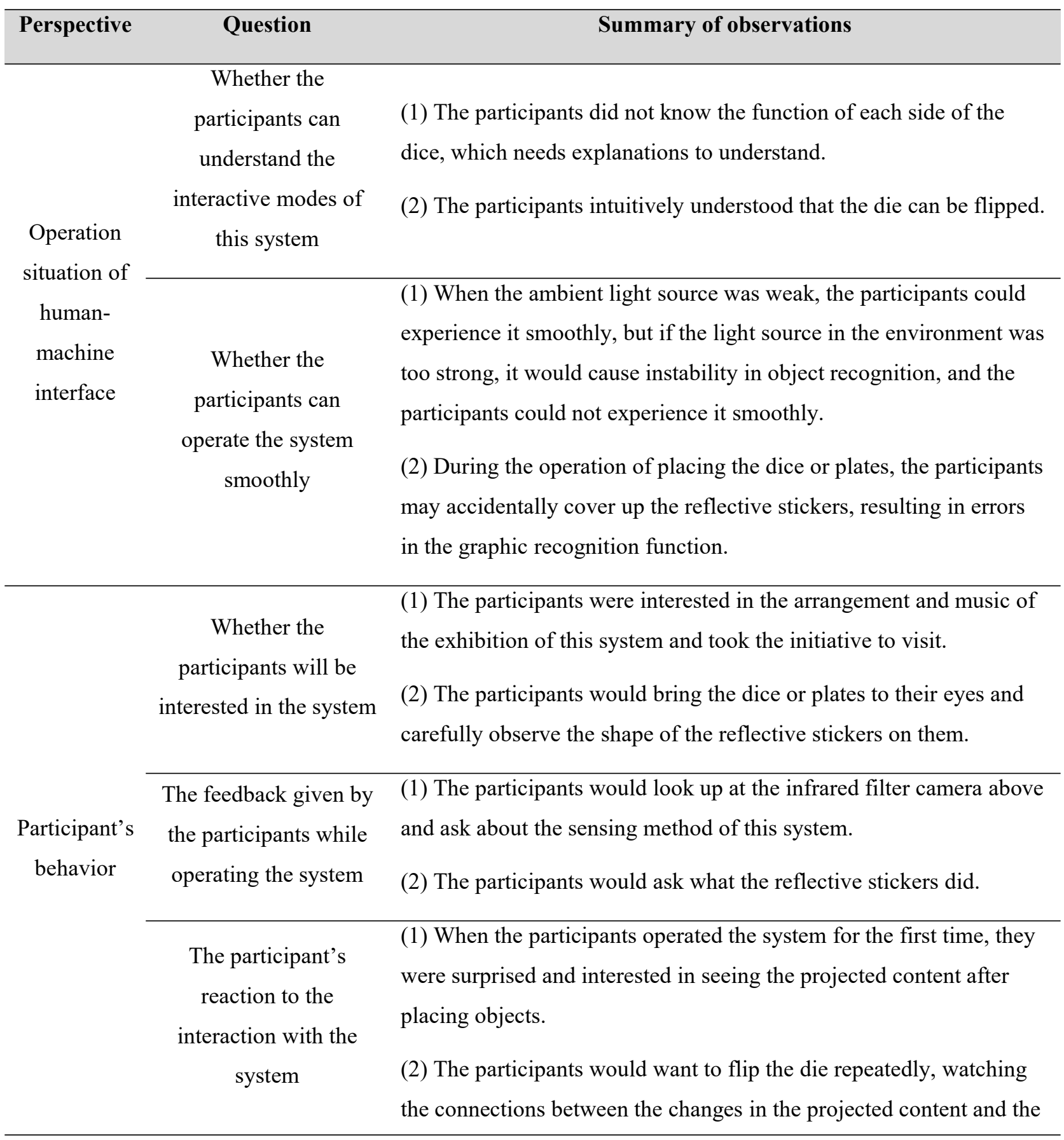


objects.

(3) The participants' attention did not stay very long in the farmland scene, but they did so in the dining table scene.

(1) The participants would try to cover the reflective stickers in various ways, or hold the plates high and shake them from side to

Additional behavior of side quickly to test whether the projected content was normal. the participant in operating the system

(2) To place objects and see clearly the contents of the projection screen, the participants leaned forward, causing displacement of the projection screen and the table board.

\subsection{Analysis of Comments Collected from Interviews with the Users}

In this study, 50 participants were randomly selected to accept interviews during the public exhibition of the proposed system. The questions asked in the interviews included three aspects, namely, "operation situation of human-machine interface," "operation experience" and "views on interactive experience of food and agricultural education." According to the answers, the number of users agreeing with each distinct opinion was counted. The results are listed in Table 10 which is summarized in the following.

(1) The operations of the proposed system were simple and easy, allowing the participants to explore freely.

(2) It is interesting and full of fun to play the system which has dynamic effects.

(3) The experiencing process not only attracts the public but also has the effect of edutainment.

(4) The action of placing objects to select food cuisines helps users to fit into interactive situations

(5) The dynamic graphic outputs may be projected for longer times to enhance the users' impressions of the interaction.

(6) More dynamic graphics and knowledge contents may be added to raise interaction and create more surprising educational effects. 
Table 10. Results of interviews with the participants about their performances of the proposed system.

\begin{tabular}{|c|c|c|}
\hline Perspective & Question & $\begin{array}{l}\text { Summary of comments } \\
(* \text { the digits in the parentheses specify the number of users making the } \\
\text { comment })\end{array}$ \\
\hline $\begin{array}{l}\text { Operation } \\
\text { situation of } \\
\text { human- }\end{array}$ & $\begin{array}{l}\text { What is your } \\
\text { opinion on the } \\
\text { projection-based } \\
\text { interaction by } \\
\text { placing objects? }\end{array}$ & $\begin{array}{l}\text { (1) Most participants believed that the projection-based interaction by } \\
\text { placing objects was a novel and interesting way of experiencing. (39) } \\
\text { (2) Most participants believed that the projection-based interaction by } \\
\text { placing objects was a convenient and easy to understand way of } \\
\text { experiencing. (38) } \\
\text { (3) Many participants were curious about the sensing mode of interactive } \\
\text { projection and wanted to understand its principle further. (24) }\end{array}$ \\
\hline $\begin{array}{l}\text { machine } \\
\text { interface }\end{array}$ & $\begin{array}{l}\text { What's your } \\
\text { opinion on the } \\
\text { operations of the } \\
\text { interface of the } \\
\text { system? }\end{array}$ & $\begin{array}{l}\text { (1) Most participants believed that the interfaces were simple and easy to } \\
\text { operate. (36) } \\
\text { (2) Some participants said that the system could be played without any } \\
\text { hints, allowing them to explore freely. (11) } \\
\text { (3) Some participants thought that this work should remind them of the } \\
\text { function of dice and plates, so that they could know how to operate. (12) }\end{array}$ \\
\hline \multirow[t]{2}{*}{$\begin{array}{l}\text { Operation } \\
\text { experience }\end{array}$} & $\begin{array}{l}\text { What is your } \\
\text { opinion on the } \\
\text { layout of the } \\
\text { exhibition or the } \\
\text { design of the } \\
\text { digital content? }\end{array}$ & $\begin{array}{l}\text { (1) Many participants thought that the digital content of the system was rich } \\
\text { and aesthetic. (32) } \\
\text { (2) Some participants thought that the reflective stickers on the plates were } \\
\text { too obvious, which would affect the aesthetics of projection effects. (12) } \\
\text { (3) Most participants liked the feedback that food would appear on plates } \\
\text { and smoke would be generated. (31) } \\
\text { (4) Most participants liked the feedback of projecting dynamic effects } \\
\text { around objects. (36) } \\
\text { (5) Many participants thought that the feedback of dynamic effects was } \\
\text { quite static, and more unexpected dynamic effects feedbacks could be added } \\
\text { to increase the sense of surprise. (21) }\end{array}$ \\
\hline & $\begin{array}{l}\text { What do you } \\
\text { think of the } \\
\text { educational } \\
\text { nature of this } \\
\text { system about } \\
\text { food and }\end{array}$ & $\begin{array}{l}\text { (1) Many participants thought that they could learn what ingredients were } \\
\text { used to make each plate food by playing the system. (20) } \\
\text { (2) Some participants thought that more knowledge about food and } \\
\text { agricultural education could be expanded. (15) } \\
\text { (3) A few participants thought that the information about food and } \\
\text { agricultural education did not last long enough, and they might forget it }\end{array}$ \\
\hline
\end{tabular}




\begin{tabular}{|c|c|c|}
\hline & $\begin{array}{l}\text { agricultural } \\
\text { knowledge? }\end{array}$ & after reading it. (4) \\
\hline & $\begin{array}{l}\text { What are your } \\
\text { thought and } \\
\text { feeling in the } \\
\text { process of } \\
\text { playing this } \\
\text { system? }\end{array}$ & $\begin{array}{l}\text { (1) Most participants felt that the way to play the system was fun and } \\
\text { interesting. (40) } \\
\text { (2) Some participants thought that the layout and arrangement of the plates } \\
\text { in the exhibition made them fit into the dining table situation very well. (18) } \\
\text { (3) Some participants believed that the interactivity of the system could be } \\
\text { enhanced further, and it would be more interesting to add some game } \\
\text { mechanisms. (9) }\end{array}$ \\
\hline $\begin{array}{l}\text { Views on } \\
\text { interactive } \\
\text { experience } \\
\text { of food and } \\
\text { agricultural } \\
\text { education }\end{array}$ & $\begin{array}{l}\text { What is your } \\
\text { opinion on } \\
\text { applying the } \\
\text { experiencing } \\
\text { process of the } \\
\text { interactive } \\
\text { projection table } \\
\text { to food and } \\
\text { agricultural } \\
\text { education? }\end{array}$ & $\begin{array}{l}\text { (1) All participants agreed that it was appropriate to apply the experiencing } \\
\text { process using the interactive projection table to food and agricultural } \\
\text { education. (50) } \\
\text { (2) Many participants thought that applying the experiencing process of the } \\
\text { interactive projection table to food and agricultural education had the effect } \\
\text { of edutainment. (28) }\end{array}$ \\
\hline
\end{tabular}

\subsection{Analysis of Comments Collected from Interviews with the Experts}

In the interviews with the four invited experts, three aspects of questions, namely, "operation situation of human-machine interface," "experiencing the educational content of the system," and "view on the interactive experiencing process," were asked. Their comments are listed in Table 11 which can be summarized as follows.

Table 11. Results of interviews with the experts about the proposed system.

\begin{tabular}{ccl}
\hline Perspective & Question & \multicolumn{1}{c}{ Summary of comments } \\
\hline \multirow{3}{*}{$\begin{array}{c}\text { Operation } \\
\text { situation of } \\
\text { human- } \\
\text { the interface of the } \\
\text { machine }\end{array}$} & $\begin{array}{c}\text { system? } \\
\text { interface }\end{array}$ & $\begin{array}{l}\text { (1) A, B and D believed that the operation of the system was } \\
\text { intuitive and easy, and the placement had no specific sequence, } \\
\text { which enabled participants to try freely. }\end{array}$ \\
\cline { 2 - 3 } & process of this work is & $\begin{array}{l}\text { (1) A, B and D mentioned that object recognition was accurate, and } \\
\text { the image feedback was in real-time, so the overall performance } \\
\text { experience was smooth. }\end{array}$ \\
& smooth? & $\begin{array}{l}\text { (2) A, B and D thought that the sensing sensitivity of the system was } \\
\text { affected by external light interference, so attention should be paid to }\end{array}$ \\
\hline
\end{tabular}


the control of light sources of the exhibition.

(3) C believed that even if there was a delay on the display for technical reasons, it depended on the operation situation of the system, and sometimes the delay could be allowed.

\begin{tabular}{|c|c|c|}
\hline & $\begin{array}{l}\text { How do you feel about } \\
\text { the layout of the } \\
\text { exhibition or the } \\
\text { design of the digital } \\
\text { content? }\end{array}$ & $\begin{array}{l}\text { (1) A believed that the physical plates and the projection had the } \\
\text { effect of virtual and real co-construction. } \\
\text { (2) C indicated that it was not easy for participants to understand the } \\
\text { function of the dice, so it was necessary to make a packaging or } \\
\text { consider using real dishes or models to present. }\end{array}$ \\
\hline $\begin{array}{c}\text { Experiencing } \\
\text { the }\end{array}$ & $\begin{array}{c}\text { Do you think this work } \\
\text { has achieved an } \\
\text { entertaining effect? }\end{array}$ & $\begin{array}{l}\text { (1) A, B and D all thought the operation mode of the system was } \\
\text { interesting and could attract people to experience it. }\end{array}$ \\
\hline $\begin{array}{l}\text { educational } \\
\text { content of } \\
\text { the system }\end{array}$ & $\begin{array}{l}\text { What do you think of } \\
\text { the educational nature } \\
\text { of this work on food } \\
\text { and agricultural } \\
\text { knowledge? }\end{array}$ & $\begin{array}{l}\text { (1) A and D thought that nowadays people paid more attention to the } \\
\text { health and safety of diet, so relevant knowledge could be added. } \\
\text { (2) B suggested that the farmland scene could also include } \\
\text { information on the origin of food to form a concept of closer linking } \\
\text { the origin to the dining table. } \\
\text { (3) C believed that if participants wanted to experience the context } \\
\text { behind the dishes, they should really go to the context of dishes, } \\
\text { analyze and sort out the contents of food for agricultural education in } \\
\text { detail, and increase the educational depth of the system. }\end{array}$ \\
\hline $\begin{array}{l}\text { View on the } \\
\text { interactive } \\
\text { experiencing } \\
\text { process }\end{array}$ & $\begin{array}{l}\text { How do you feel about } \\
\text { the application of the } \\
\text { experience form of } \\
\text { interactive projection } \\
\text { table to food and } \\
\text { agricultural education? }\end{array}$ & $\begin{array}{l}\text { (1) A, B and D all believed that the experience form of the } \\
\text { interactive projection table could make the general people feel novel } \\
\text { and interesting. } \\
\text { (2) B indicated that the operation of the interactive projection table } \\
\text { was inherently interesting, which could also enhance the } \\
\text { participants' knowledge in this respect. } \\
\text { (3) B thought that the experience of operating the interactive } \\
\text { projection table would be attractive to urban children or adults. }\end{array}$ \\
\hline
\end{tabular}

(1) The experience of playing the proposed system is both entertaining and educational.

(2) The interface with no specific play sequence is intuitive and easy to use, allowing free explorations.

(3) The system can display real-time feedbacks, and the overall experiencing process is 
smooth.

(4) The appearance of the crop dice may be modified further to enhance its linkage to food materials.

(5) Presenting related knowledge via an interactive projection table can attract the public to experience the system and deepen their impressions of the knowledge.

(6) More examples of "food serving from the origin to the dining table," as well as knowledge about diet safety and healthy diet, may be added to enrich the content and depth of food and agricultural education.

\subsection{The Findings of the Proposed System}

After literature reviews of related human-machine interaction theories and existing cases of interactive devices, an interactive system "iFood on iTable" with a projection table using simple patterns as the interfaces has been designed for food and agricultural education. The interaction capability of the system is realized by the uses of computer vision techniques using the infrared filter camera as the sensor. The education content is taught in the way of playing a game of understanding the entire food preparation process "from the food origin to the dining table." During the public display of the system, the observation and interview methods were used to collect relevant data and comments from the participants and experts, and the effectiveness of the proposed system was evaluated accordingly to the following findings.

(1) The recognition of the simple shapes using the computer vision technology can realize effective human-machine interaction ---

In this study, the shapes of triangles, squares, pentagons, and circles are used as the object features in the interface, which are simple but effective for shape recognition by the computer vision technology to accelerate the human-machine interaction process, leading to quick and correct feedbacks yielded by the system and let the participants have a very smooth experience.

(2) The object-based interfaces helped the participants fit into the context of education ---

This advantage comes from the uses of computer vision techniques that increase the freedom of interaction, allowing the participants to explore the experiencing process freely and achieving the effect of edutainment.

(3) The interactive experience of performing the proposed system is appealing and amusing -

The interaction allows the participants to absorb the knowledge of food production through game 
plays by projecting the related knowledge onto the table which creates dynamic effects of edutainment.

(4) The interactive experience could be combined with richer dynamic images and related knowledge contents to enhance the educational effect ---

The purpose of interaction via the system is for participants to learn by plays; and if more images and knowledge contents can be added, the participants will be more willing to participate.

\section{Conclusions}

With the advance of media technology, new ways of experiencing the learning and extension of food and agricultural education become feasible. A simple interactive system based on the projection mapping approach as well as the use of computer vision technology has been proposed in this study to offer a new experiencing process for food and agricultural education. According to the facts found from the activities of observations and interviews involving invited users and experts in the public exhibition of the proposed system, it is concluded that the proposed computer vision-based system can indeed offer an attractive interactive experiencing process for food and agricultural education, which is simple and effective due to the use of simple feature shapes for object recognition in human-machine interfacing.

The cuisines used in the proposed system for game playing are just examples; however, the issue of food and agricultural education dealt with in this paper is general. In the future, the cuisines used in the system can be easily replaced by those of any country or region to make the resulting system fit local educational applications. Furthermore, it is also worth trying to include more advanced techniques like virtual reality, augmented reality, and mixed reality into the designs of interactive system. Finally, about the evaluation of the effectiveness of the proposed system for food and agricultural education, the additional method of questionnaire survey with users divided into experimental and control groups may be adopted.

\section{References}

[1] Food and Agriculture Organization of the United Nations (2014): Biodiversity for Food and Agriculture: Contributing to Food Security and Sustainability in a Changing World. Available online: http://www.fao.org/family-farming/detail/en/c/284748/ (accessed on 23 June 2020). 
[2] Boccaletti, S. Environmentally responsible food choice. OECD Journal: General Papers 2008, $2,117-152$.

[3] Tscharntke, T.; Clough, Y.; Wanger, T. C.; Jackson, L.; Motzke, I.; Perfecto, I.; Whitbread, A. Global food security, biodiversity conservation and the future of agricultural intensification. Biological conservation 2012, 151, 53-59.

[4] Konuma, H. Status of world food security and its future outlook, and role of agricultural research and education. Journal of Developments in Sustainable Agriculture 2016, 10, $69-75$.

[5] Kimura, A. H. Food education as food literacy: privatized and gendered food knowledge in contemporary Japan. Agriculture Human Values 2011, 28, 465-482.

[6] Morita T. Background and situation of dietary education - In connection with the "Basic Food Education Bill. Survey and Information (調査と情報) 2004, 457, 1-10 (in Japanese).

[7] Uenaka O. Significance and issues of local production for local consumption in food and agriculture education. Educational Studies Review (教育学論究) 2013, 7, 47-53 (in Japanese).

[8] Malik, S.; Agarwal, A. Use of multimedia as a new educational technology tool-A study. International Journal of Information and Education Technology 2012, 2, 468-471.

[9] Jeng, T.; Lee, C.-H.; Chen, C.; Ma, Y. Interaction and Social Issues in a Human-Centered Reactive Environment. Proceedings of 7 th International Conference on Computer Aided Architectural Design Research in Asia (CAADRIA), Cyberjaya, Malaysia, Apr. 18-20, 2002; pp. 258-292.

[10] Crowley, J. L.; Coutaz, J. Vision for Man Machine Interaction. Proceedings of IFIP International Conference on Engineering for Human-Computer Interaction (EHCI'95), Grand Targhee, Wyoming, USA, Aug. 1995; pp. 28-45.

[11] Turk, M. Computer vision in the interface. Communications of the ACM 2004, 47, 60-67.

[12] Jaimes, A.; Sebe, N. Multimodal human-computer interaction: A survey. Computer Vision And Image Understanding 2007, 108, 116-134.

[13] Wilson, A. D. PlayAnywhere: a Compact Interactive Tabletop Projection-Vision System. Proceedings of 18th Annual ACM Symposium on User Interface Software and Technology (UIST '05), Seattle, WA, USA, Oct. 23-27, 2005; pp. 83-92.

[14] Hsu, H. M. J. The potential of Kinect in education. International Journal of Information and Education Technology 2011, 1, 365-370. 
[15] Geller, T. Interactive tabletop exhibits in museums and galleries. IEEE Computer Graphics Applications 2006, 26, 6-11.

[16] Fujii Y. Sagen Ishizuka's dietary education and dietary method: A study on the intellectual framework of nutrition therapy 11. Bulletin of Faculty of Human Life Studies, Fuji Women's University 2014, 51, 25-38 (in Japanese).

[17] National Chengchi University Aboriginal Studies Center. Food farmers education in the United States. Aboriginal Education World 2018, 81, 74-77 (in Chinese).

[18] Petrini, C. Slow food nation: Why Our Food Should Be Good, Clean, and Fair; Rizzoli Publications: New York, NY, USA, 2013.

[19] Powell, D.; Agnew, D.; Trexler, C. Agricultural literacy: Clarifying a vision for practical application. Journal of Agricultural Education 2008, 49, 85-98.

[20] Asaoka, Y. Practice of New Environmental Education; Kobundo: Tokyo, Japan, 2005 (in Japanese).

[21] NAAE: What is Agricultural Education? Available online: https://www.naae.org/whatisaged/ (accessed on 26 July 2020).

[22] Kantowitz, B. H.; Sorkin, R. D. Human Factors: Understanding People-System Relationships; John Wiley \& Sons Inc.: Hoboken, NJ, USA, 1983.

[23] Deng, L.; Wang, G.; Yu, S. Layout design of human-machine interaction interface of cabin based on cognitive ergonomics and GA-ACA. Computational Intelligence and Neuroscience 2016, 2016, 1-12.

[24] Ye J. Introduction to Interactive Design; Artist: Taipei, Taiwan, ROC, 2010 (in Chinese).

[25] Jaimes, A.; Sebe, N. Multimodal human-computer interaction: A survey. Computer Vision and Image Understanding 2007, 108, 116-134.

[26] Ahamed, M. M.; Bakar, Z. B. A. Triangle model theory for enhance the usability by user centered design process in human computer interaction. International Journal on Contemporary Computer Research 2017, 1, 26-32.

[27] Szeliski, R. Computer Vision: Algorithms and Applications; Springer: New York, NY, USA, 2010.

[28] Hu, W.; Tan, T.; Wang, L.; Maybank, S. A survey on visual surveillance of object motion and behaviors. IEEE Trans. on Systems, Man, Cybernetics, Part C (Applications and Reviews) 2004, 34, 334-352.

[29] Ojha, S.; Sakhare, S. Image Processing Techniques for Object Tracking in Video Surveillance-A Survey. Proceedings of 2015 International Conference on Pervasive Computing (ICPC), Pune, India, Jan. 09-10, 2015; pp. 1-6. 
[30] Ragland, K.; Tharcis, P.; Wang, L. A survey on object detection, classification and tracking methods. Engineering Research \& Technology 2014, 3,: 622-628.

[31] Iraola, A. B. Skeleton Based Visual Pattern Recognition: Applications to Tabletop Interaction. PhD Dissertation, The University of the Basque Country, Leioa, BI, Spain, 2009.

[32] Crowley, J. L.; Coutaz, J.; Bérard, F. Things that see. Communications of the ACM 2000, 43, $54-64$.

[33] Wang, C. M.; Wu, T. D. A new investigation of technology art - A study of applying computer vision techniques to interactive context. Journal of National Taiwan College of Arts 2005, 76, 113-130。

[34] Hassenzahl, M.; Diefenbach, S.; Göritz, A. Needs, affect, and interactive products - Facets of user experience. Interacting with Computers 2010, 22, 353-362.

[35] Pine, B. J.; Gilmore, J. H. Welcome to the experience economy. Harvard Business Review 1998, 76, 97-105.

[36] Mitchell, A.; Linn, S.; Yoshida, H. A tale of technology and collaboration: Preparing for 21st-century museum visitors. Journal of Museum Education 2019, 44, 242-252.

[37] ReacTj (2009): ReacTj - ReacTable Trance Live Performance \#2. Available online: https://www.youtube.com/watch?v=Mgy1S8qymx0 (accessed on 5 July 2020).

[38] TeamLab. (2013): A Table Where Little People Live. Available online: https://www.teamlab.art/w/kobitotable (accessed on 9 July 2020).

[39] TeamLab. (2015): Worlds Unleashed and Then Connecting. Available online: https://www.teamlab.art/w/worlds-unleashed-restaurant/ (accessed on 9 July 2020).

[40] TeamLab. (2017): Connecting! Block Town. Available online: https://www.teamlab.art/w/block-town/ (accessed on 9 July 2020).

[41] Rumu Innovation (2018): Happy Farmer. Available online: https://www.rumuinno.com/happy-farmer (accessed on 9 July 2020).

[42] Buchenau, M.; Suri, J. F. Experience Prototyping. Proceedings of the 3rd Conference on Designing Interactive Systems: Processes, Practices, Methods, and Techniques. New York, NY, USA, 2000; pp. 424-433.

[43] Naumann, J. D.; Jenkins, A. M. Prototyping: the new paradigm for systems development. MIS Quarterly 1982, 3, 29-44.

[44] Eliason, A. L. System Development: Analysis, Design, and Implementation; Scott Foresman \& Co.: Northbrook, IL, USA, 1990. 
[45] Lidwell, W.; Holden, K.; Butler, J. Universal Principles of Design, Revised and Updated: 125 Ways to Enhance Usability, Influence Perception, Increase Appeal, Make Better Design Decisions, and Teach Through Design; Rockport: Beverly, MA, USA, 2010.

[46] Ye Z.; Ye L. Research Methods and Essay Writing; Shangding Culture: Taipei, Taiwan, ROC, 1999 (in Chinese).

[47] Yoo, H., Kim, H. A Study on the Media Arts Using Interactive Projection Mapping, Contemporary Engineering Sciences, 2014, 7, no. 23, 1181-1187. 